\title{
Insulin action in growth hormone-deficient and age-matched control rats: effect of growth hormone treatment
}

\author{
J R Daugaard, J L Laustsen, B S Hansen ${ }^{\mathbf{1}}$ and E A Richter \\ Copenhagen Muscle Research Centre, August Krogh Institute, Copenhagen, Denmark \\ ${ }^{1}$ Novo Nordisk, Bagsværd, Denmark \\ (Requests for offprints should be addressed to J R Daugaard, Copenhagen Muscle Research Centre, August Krogh Institute, 13 Universitetsparken, \\ DK-2100 Copenhagen $\varnothing$, Denmark)
}

\begin{abstract}
The isolated effect of growth hormone on carbohydrate metabolism in rat skeletal muscle was studied in growth hormone-deficient dwarf rats $(\mathrm{dw} / \mathrm{dw})$ treated with either recombinant human growth hormone or saline for 10 days. In addition, age-matched heterozygous (DW/dw) (normal weight and plasma IGF-I) control rats were treated with saline. Growth hormone increased weight gain from $0 \cdot 1 \pm 0 \cdot 1$ (s.E.M) to $3 \cdot 6 \pm 0 \cdot 1 \mathrm{~g} /$ day and plasma IGF-I concentration from $364 \pm 23$ to $451 \pm 32 \mathrm{ng} / \mathrm{ml}$. Glucose metabolism in skeletal muscle perfused with basal, submaximal and maximal concentrations $(0,600$ and $60000 \mathrm{pmol} / 1$ respectively) of insulin was not changed by growth hormone. No change could be detected in the total number of glucose transporters (GLUT1 and GLUT4) in the skeletal muscles, except from a lower amount of GLUT4 in the soleus muscle in the hetero-
\end{abstract}

zygous control group. However, at submaximal insulin concentrations, skeletal muscle glucose uptake and transport were significantly lower in the heterozygous control group compared with the growth hormone-deficient group. This could indicate either a direct long-term effect of growth hormone or more likely a secondary effect attributable to the difference in body weight $(205 \cdot 2 \pm 3 \cdot 1$ vs $361 \cdot 6 \pm 5.9 \mathrm{~g}$ for dwarf rats and heterozygous controls respectively), and thereby muscle fibre size, between the groups probably resulting in lower average interstitial insulin and glucose concentrations at a given plasma concentration in the heterozygous rats. It is concluded that restoration of subnormal growth hormone concentrations for 10 days has no effect on insulin-stimulated glucose metabolism in skeletal muscle in vitro.

Journal of Endocrinology (1999) 160, 127-135

\section{Introduction}

Growth hormone has been used for treatment of growth hormone-deficient patients for several decades. Whereas the growth-promoting effects of treatment with growth hormone are unequivocal, the effects on metabolism of fat and carbohydrate in skeletal muscle are not known in any detail. In normal man, sustained increased levels of growth hormone have been found to result in impairment of peripheral insulin sensitivity (Bratusch-Marrain et al. 1982, Møller et al. 1989). Interestingly, when studying insulin action in growth hormone-deficient patients, where the effect of restoring subnormal growth hormone levels to normal can be studied, the picture is less clear. In these patients, who are prone to hypoglycaemia during childhood (Goodman et al. 1968, Hopwood et al. 1975) but insulin resistant during adulthood (Johansson et al. 1995, Hew et al. 1996), long-term replacement treatment with recombinant human growth hormone (rhGH) has revealed conflicting results (Fowelin et al. 1993, Hussain et al. 1994, Jørgensen et al. 1994, O'Neal et al. 1994, Weaver et al. 1995).
The mechanism behind the growth hormone-induced changes in insulin action is not known, but since the primary site of insulin-mediated glucose uptake is skeletal muscle the insulin resistance following treatment with growth hormone has been studied in this tissue. Both relatively old (Bratusch-Marrain et al. 1982, Rizza et al. 1982, Rosenfeld et al. 1982) and newer studies (Møller et al. 1989, Bak et al. 1991) suggest that the decrease in insulin sensitivity in skeletal muscle following treatment with growth hormone on top of normal levels can, at least in part, be explained by a defect distal to the insulin receptor.

In rats, the effect of growth hormone on insulin action in skeletal muscle has been studied both in vivo and in vitro adding extra growth hormone to normal $(\mathrm{Ng}$ et al. 1990, Dimitriadis et al. 1994, Cartee \& Bohn 1995, Hittiarachchi et al. 1996, Napoli et al. 1996) and to hypophysectomised rats (Manchester et al. 1959, Riddick et al. 1962). The studies have revealed conflicting results, some showing a decrease in insulin sensitivity in skeletal muscle following treatment with growth hormone (Manchester et al. 1959, Riddick et al. 1962, Ng et al. 
1990, Dimitriadis et al. 1994, Cartee \& Bohn 1995, Hittiarachchi et al. 1996) and others showing no such effect (Napoli et al. 1996). Since in skeletal muscle the glucose transporters GLUT1 and GLUT4 are thought to be responsible for the basal and insulin-stimulated glucose transport respectively (Richter 1996) these transport proteins have been studied in some detail. The studies seem to agree that in skeletal muscle, growth hormone has no effect on the total number of GLUT4 (Cartee \& Bohn 1995, Napoli et al. 1996) whereas no clear-cut picture exists for GLUT1, with one study showing a small decrease in the total number of GLUT1 following treatment with rhGH (Napoli et al. 1996) and another showing no such effect (Cartee \& Bohn 1995).

The above mentioned studies in rats suffer from some methodological problems. For instance, when adding exogenous growth hormone to rats with normal growth hormone levels one is studying the effect of supraphysiological, not physiological, concentrations of growth hormone. Furthermore, the hypophysectomised rat is not a model of isolated growth hormone deficiency because all pituitary hormones are lacking. To circumvent these problems and to be able to elucidate the isolated effects of long-term replacement treatment (10 days) with growth hormone on skeletal muscle insulin action, we have chosen the growth hormone-deficient rat (dw/dw) (Charlton et al. 1988) as our model. The $\mathrm{dw} / \mathrm{dw}$ rat arose from a spontaneous mutation and it is characterised by having a very low growth hormone secretion $(5-10 \%$; of normal) whereas all other known pituitary hormones are found in normal levels (Charlton et al. 1988). As our control animal a group of heterozygous age-matched control rats (normal weight and plasma insulin-like growth factor-I (IGF-I)) was chosen, since age is known to influence insulin action in both rat (Goodman et al. 1983) and human (Fink et al. 1983) skeletal muscle.

\section{Materials and Methods}

Forty-eight adult (21-23 weeks old) male growth hormone-deficient rats (DW-4/OLA/HSD/NN) homozygous for the dwarf (dw/dw) trait, were obtained from Novo Nordisk, Bagsvard, Denmark, and 21 adult (21-23 weeks old) male rats (DW-4/OLA/HSD) heterozygous for the dwarf (Dw/dw) trait were obtained from Harlan UK Ltd, Bicester, UK. Upon arrival the rats were housed individually in plastic cages with a controlled temperature $\left(20^{\circ} \mathrm{C}\right)$ and a $12 \mathrm{~h}: 12 \mathrm{~h}$ light-darkness cycle. Lights were on at $0800 \mathrm{~h}$. After 4 weeks the growth hormone-deficient rats were randomly assigned to placebo (PLA) or rhGHtreated $(\mathrm{GH})$ groups. The heterozygous rats were agematched controls (AGE). The rats were weighed in the morning and received s.c. injections twice daily at 0900 and $1700 \mathrm{~h}$, for 10 consecutive days. The GH group was injected with rhGH (Norditropin, Novo Nordisk)
$(0.25 \mathrm{mg} / \mathrm{kg}$ body weight $)$ dissolved in sterile saline containing $0.5 \%$; bovine serum albumin (BSA) (Cohn fraction V, Sigma Chemical Co., St Louis, MO, USA), which had been passed through a sterile filter, and the PLA group was injected with an equivalent volume of vehicle. BSA was added to minimise rhGH binding to plastic. The AGE group was treated as the PLA group. Rats had free access to standard rat chow (Altromin nr. 1324, Chr. Petersen, Ringsted, Denmark) and tap water until killing. The amount of rat chow remaining in the cage was weighed every morning. The morning after the last evening rhGH injection, animals were again weighed and thereafter anaesthetised with pentobarbital sodium $(50 \mathrm{mg} / \mathrm{kg}$ body weight). Since the rats were fed the night before the perfusion and the food was removed in the morning 3-7 $\mathrm{h}$ before the experiment they must be considered to be under post-prandial conditions.

The rats were surgically prepared for hindlimb perfusion according to Ruderman et al. (1971). Before inserting the catheters the rats were heparinised with 500 IU heparin in the inferior vena cava. Blood for analysis of glucose, insulin and IGF-I was sampled from the catheter in the inferior vena cava. Then the rats were killed and the hindlimbs were subsequently perfused.

The perfusion apparatus was similar to that described by Ruderman et al. (1971). To maintain the temperature of the perfusate at $37^{\circ} \mathrm{C}$, a heating coil was inserted into the system. The perfusate consisted of Krebs-Henseleit solution, 1- to 3-day-old washed bovine erythrocytes at a haematocrit of $30 \%$; $4 \%$; BSA, $8 \mathrm{mM}$ glucose, $0.15 \mathrm{mM}$ pyruvate, $1 \mathrm{mM}$ mannitol and $4 \cdot 2 \mathrm{IU} / \mathrm{ml}$ heparin. The $\mathrm{pH}$ of the perfusate was adjusted using bicarbonate and it was continuously gassed during perfusion with a mixture of $35 \% \mathrm{O}_{2}, 3 \% \mathrm{CO}_{2}$ and $62 \% \mathrm{~N}_{2}$, yielding an arterial $\mathrm{pH}$ of 7.39 $\pm 0.01(n=68)$ (mean \pm S.E.M.), $\mathrm{CO}_{2}$-pressure of $35.0 \pm 0.5 \mathrm{mmHg} \quad(n=69)$ and an $\mathrm{O}_{2}$-pressure of $225.9 \pm 3.1 \mathrm{mmHg} \quad(n=69)$. Insulin (Actrapid, Novo Nordisk) in the following concentrations was used: 0 (basal (BAS)), 600 (submaximal (SUB)) and 60000 (maximal $(\mathrm{MAX})) \mathrm{pmol} / 1$ cell-free perfusate. Insulin at $60000 \mathrm{pmol} / 1$ is a maximally stimulating insulin concentration in the perfused hindquarter (Richter et al. 1984).

The first $25 \mathrm{ml}$ of perfusate that passed through the rat was discarded, after which the perfusate was recirculated at a flow rate of $12.5 \mathrm{ml} / \mathrm{min}$. Perfusate samples were obtained from the arterial inflow and venous outflow tubing. Immediately following perfusion the soleus (SOL) and the extensor digitorum longus (EDL) from both legs were rapidly dissected out, freeze clamped and stored at $-80{ }^{\circ} \mathrm{C}$ until analysis.

To measure muscle membrane glucose transport, 3-O-[glucose- ${ }^{14} \mathrm{C}(\mathrm{U})$ ] methyl-D-glucose (specific activity $315 \mathrm{mCi} / \mathrm{mmol})$ and $\mathrm{D}-\mathrm{mannitol}-\left[1-{ }^{3} \mathrm{H}(\mathrm{N})\right]$ (specific activity $22.5 \mathrm{mCi} / \mathrm{mmol}$ ) were added simultaneously to the perfusate, yielding an activity of 0.075 and $0.10 \mu \mathrm{Ci} / \mathrm{ml}$ respectively. To avoid significant 
efflux of 3-O-[glucose- ${ }^{14} \mathrm{C}(\mathrm{U})$ ] methyl-D-glucose from the intracellular space, the duration of exposure to isotopically labelled compounds was varied depending on the expected glucose transport during the different insulin concentrations. In BAS, SUB and MAX the hindlimb was exposed to the isotopically labelled compounds for 31, 12 and $7 \mathrm{~min}$ respectively, always beginning $20 \mathrm{~min}$ after starting the perfusion. At the time when the isotopically labelled compounds reached the muscles, recirculation of the perfusate was stopped and one-way perfusion was commenced to secure a constant specific activity of glucose in the arterial perfusate during the period of glucose transport measurement.

Plasma glucose was measured with a Yellow Springs Glucose Analyzer (model 2700 select, Yellow Springs, $\mathrm{OH}$, USA). Insulin in plasma was determined by a commercially available RIA kit especially designed for measurement of rat insulin (Amersham International, Amersham, Bucks, UK). The coefficient of variation of the assay was 5\%. IGF-I in plasma was also determined using an RIA. The primary antibody was raised against human IGF-I and the secondary antibody was a sheep anti-rabbit (UCB, Brussels, Belgium). As tracer a monoiodinated isomer, ${ }^{125} \mathrm{I}(\mathrm{Tyr})-\mathrm{IGF}-\mathrm{I}$ was used (Schäffer et al. 1992). The detection limit of the IGF-I assay was $0.3 \mathrm{ng} / \mathrm{ml}$; the coefficient of variation was $10 \%$.

Muscle samples were freeze dried and dissected free of blood and connective tissue before analysis. Glycogen was measured after acid hydrolysis by the hexokinase method (Lowry \& Passonneau 1972). Glucose uptake was calculated by multiplying arteriovenous differences by the flow rate and dividing by the perfused muscle mass. Muscle mass of the hindquarter was estimated as one-sixth of body weight (Ruderman et al. 1971, Richter et al. 1982).

Uptake of 3-O-[glucose- $\left.-{ }^{14} \mathrm{C}(\mathrm{U})\right]$ methyl-D-glucose in muscles $(\mu \mathrm{mol} / \mathrm{g}$ per $\mathrm{h}$ ) was detected in perchloric acid extracts and corrected for radiolabel in the extracellular space as determined by the ${ }^{3} \mathrm{H}$ counts for mannitol. Radioactivity was measured in a liquid scintillation counter (Model 2000 Tri-carb, Packard Instruments, Downers Grove, IL, USA). From the intracellular accumulation of 3-O-[glucose- ${ }^{14} \mathrm{C}(\mathrm{U})$ ] methyl-D-glucose, the rate of glucose transport was calculated using a 'specific activity of glucose' determined by the glucose concentration and 3-O-[glucose- ${ }^{14} \mathrm{C}(\mathrm{U})$ ] methyl-D-glucose counts in the perfusate.

The GLUT1 and GLUT4 content was measured in total crude muscle (TCM) membranes prepared essentially as described by Ploug et al. (1993). Twenty to thirty mg muscle were homogenised, TCM were recovered after centrifugation for $90 \mathrm{~min}$ at $100000 \boldsymbol{g}$ and stored in aliquots at $-80^{\circ} \mathrm{C}$. Protein concentrations were determined and TCM were subjected to SDS-PAGE on a gradient gel followed by transfer to a membrane. The membrane was blocked, followed by incubation with primary antibody. The GLUT4 antibody is a mouse monoclonal antibody produced against a synthetic peptide corresponding to the 13 carboxy-terminal amino acids of GLUT4 coupled with haemocyanin (Ploug et al. 1993). The GLUT1 antibody was a mouse monoclonal antibody produced against the human erythrocyte glucose transporter (Ploug et al. 1993). After incubation with primary antibody, membranes were washed and incubated with horseradish peroxidase-labelled secondary antibody. Membranes were again washed and antibody-antigen complexes were visualised by enhanced chemiluminescence. Exposures were obtained and densitometric scanning was performed.

The maximal enzymatic activities of lactate dehydrogenase (LDH), citrate synthase (CS) and $\beta$-3-hydroxyacylCoA dehydrogenase (HAD) were determined using NAD-NADH enzymatic fluorometric assays according to Lowry \& Passonneau (1972). Muscle water content was calculated as: (muscle wet weight) - (muscle freeze-dried weight).

\section{Statistics}

All results are expressed as means \pm S.E.M. Significant differences between groups were identified using a oneway ANOVA. When a significant $F$ ratio was obtained the Newman-Keul post-hoc test was utilised to identify differences between mean values. The level of significance during all tests was set at $P<0 \cdot 05$.

\section{Results}

The mean weight gain in the PLA rats was $0 \cdot 1 \pm 0 \cdot 1 \mathrm{~g} /$ day (Table 1). In GH the mean weight gain was significantly higher than in PLA at $3 \cdot 6 \pm 0 \cdot 1 \mathrm{~g} /$ day (Table 1). The mean weight gain $(-0.3 \pm 0.1 \mathrm{~g} /$ day $)$ in AGE was not different from that in PLA but significantly lower than in GH (Table 1). The growth curve demonstrates that the weight of both the PLA and the AGE group hardly changed during the 10 days of treatment, whereas the weight of the GH animals increased dramatically (Fig. 1). The food intake in the AGE group was significantly greater than that in GH and PLA (Table 1). The food intake in the GH group was significantly greater than that in PLA (Table 1). When the mean food intake per day over the 10 day treatment period was expressed per $g$ mean body weight over the same 10 day period the values were $0 \cdot 07,0 \cdot 07$ and $0.05 \mathrm{~g}$ food/g body weight per day in PLA, GH and AGE respectively. The food intake per $g$ mean body weight in AGE was significantly lower than in both PLA and GH and no difference between PLA and $\mathrm{GH}$ could be found. Thus when expressed per kg body weight the AGE rats ate less than both GH and PLA. The mean wet weights of the SOL and EDL were significantly 
Table 1 Body weight, food intake, muscle weight and water content (means \pm S.E.M.) in growth hormone-deficient rats (GH and PLA) and heterozygous age-matched control rats (AGE)

\begin{tabular}{|c|c|c|c|}
\hline & PLA & GH & AGE \\
\hline \multicolumn{4}{|l|}{ Body weight (g) } \\
\hline Before treatment $(n=24)$ & $204 \cdot 5 \pm 2 \cdot 8$ & $201 \cdot 1 \pm 2 \cdot 5$ & $364 \cdot 3 \pm 6 \cdot 0^{+}$ \\
\hline After treatment $(n=24)$ & $205 \cdot 2 \pm 3 \cdot 1$ & $237 \cdot 5 \pm 2 \cdot 3^{\#}$ & $361 \cdot 6 \pm 5 \cdot 9^{+}$ \\
\hline Food intake (g/day) $(n=24)$ & $14 \cdot 2 \pm 0 \cdot 1$ & $15 \cdot 4 \pm 0 \cdot 3^{\#}$ & $19 \cdot 0 \pm 0 \cdot 3^{+}$ \\
\hline \multicolumn{4}{|l|}{ Muscle weight (mg) } \\
\hline SOL $(n=10)$ & $64 \cdot 9 \pm 1 \cdot 6$ & $76 \cdot 3 \pm 2 \cdot 8^{\#}$ & $122 \cdot 4 \pm 4 \cdot 2^{+}$ \\
\hline $\operatorname{EDL}(n=10)$ & $106 \cdot 2 \pm 2 \cdot 3$ & $121 \cdot 0 \pm 2 \cdot 0^{\#}$ & $159 \cdot 7 \pm 4 \cdot 6^{+}$ \\
\hline \multicolumn{4}{|l|}{ Water content (\%) } \\
\hline SOL $(n=24)$ & $75 \cdot 4 \pm 0 \cdot 5$ & $75 \cdot 5 \pm 0.5$ & $76 \cdot 3 \pm 0 \cdot 4$ \\
\hline $\mathrm{EDL}(n=24)$ & $74 \cdot 4 \pm 0 \cdot 1$ & $74 \cdot 5 \pm 0 \cdot 2$ & $75 \cdot 3 \pm 0 \cdot 2^{+}$ \\
\hline
\end{tabular}

${ }^{\text {\#}}$ Significantly different from PLA, ${ }^{+}$significantly different from PLA and GH.

higher in GH than in PLA (Table 1). In AGE the mean wet weights of SOL and EDL were significantly higher than in both PLA and GH (Table 1). To evaluate whether the muscle growth was proportional to the total weight the percentage increase was calculated. When comparing the GH group and the PLA group after treatment for 10 days, body weight was increased by $13 \cdot 6 \%$, SOL weight by $14 \cdot 9 \%$ and EDL weight by $12 \cdot 2 \%$. Thus the muscle weight and the body weight seem to express proportional growth. In SOL, no difference in muscle water content was observed when the three experimental groups were

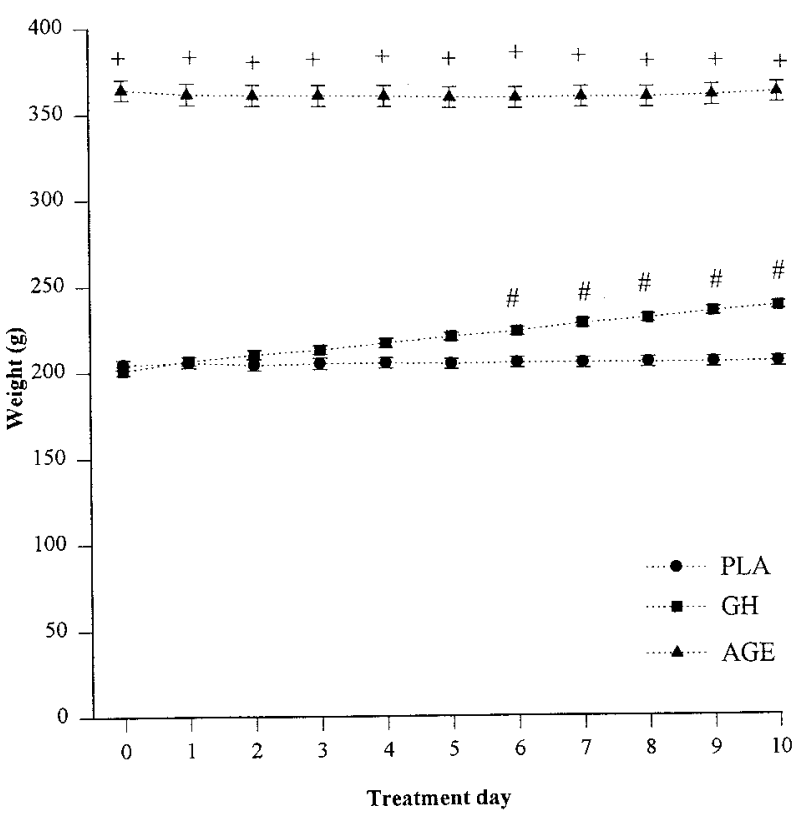

Figure 1 Growth curves of growth hormone-deficient rats $(\mathrm{GH}$ and PLA) and heterozygous age-matched control rats (AGE) during the 10 day treatment period ( $n=24$ in $\mathrm{GH}$ and PLA and $n=21$ in AGE). $\# P<0.05$ compared with PLA. $+P<0.05$ compared with PLA and $\mathrm{GH}$. Values are means \pm S.E.M. compared (Table 1). In EDL, no difference in muscle water content was observed when PLA and GH were compared, while the muscle water content in AGE was significantly higher than in both GH and PLA (Table 1).

Glucose uptake increased significantly in all groups with increasing concentrations of insulin (Fig. 2). Glucose uptake in PLA was identical to glucose uptake in GH at all insulin concentrations (Fig. 2). In AGE, glucose uptake was not significantly different from that in PLA and GH at BAS, whereas glucose uptake was significantly lower at SUB and MAX (Fig. 2).

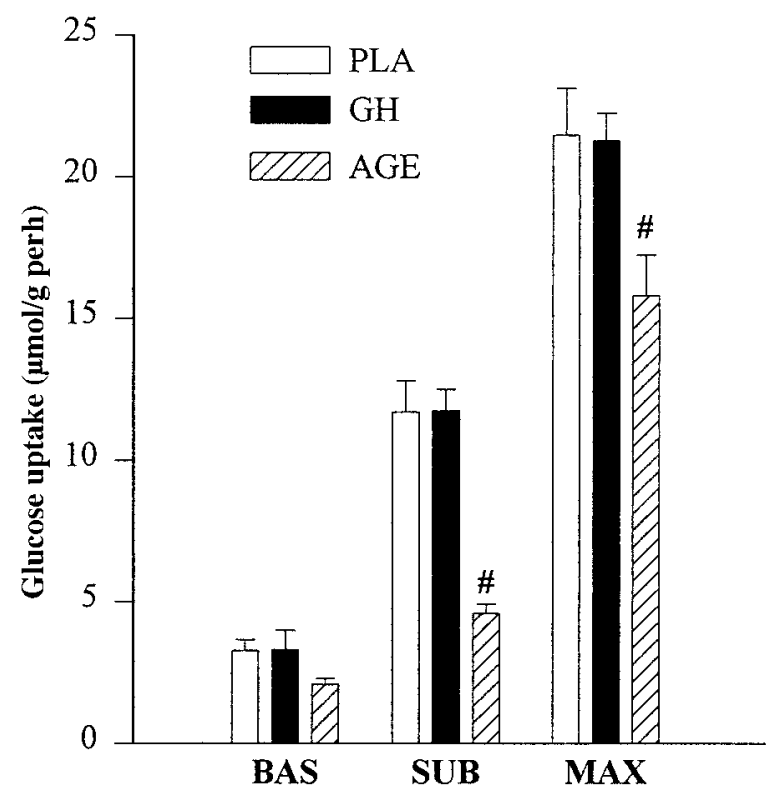

Figure 2 Glucose uptake was measured as arteriovenous difference multiplied by the perfusate flow rate in growth hormone-deficient rats ( $\mathrm{GH}$ and PLA) and heterozygous age-matched control rats (AGE). Hindlimbs were perfused with insulin concentrations at 0 (BAS), 600 (SUB) and $60000 \mathrm{pmol} / \mathrm{l}$ $(\mathrm{MAX})(n=8$ in each of the nine groups). $\# P<0.05$ compared with PLA and GH. Values are means \pm S.E.M. 
Table 2 Glucose transport in individual skeletal muscles in growth hormone-deficient rats (GH and PLA) and heterozygous age-matched control rats (AGE). Values are means \pm S.E.M.

\begin{tabular}{|c|c|c|c|}
\hline & PLA & GH & AGE \\
\hline \multicolumn{4}{|c|}{ SOL $(\mu \mathrm{mol} / \mathrm{g}$ per $\mathrm{h})$} \\
\hline BAS & $2 \cdot 0 \pm 0 \cdot 4$ & $3 \cdot 0 \pm 0 \cdot 6$ & $1 \cdot 2 \pm 0 \cdot 1^{\S}$ \\
\hline SUB & $11 \cdot 6 \pm 1 \cdot 2^{*}$ & $12 \cdot 5 \pm 1 \cdot 1^{*}$ & $4 \cdot 6 \pm 0 \cdot 8^{*,+}$ \\
\hline MAX & $27 \cdot 8 \pm 3 \cdot 6^{\wedge}$ & $23 \cdot 4 \pm 2 \cdot 1^{\wedge}$ & $22 \cdot 7 \pm 1 \cdot 4^{\wedge}$ \\
\hline \multicolumn{4}{|c|}{ EDL $(\mu \mathrm{mol} / \mathrm{g}$ per $\mathrm{h})$} \\
\hline BAS & $1 \cdot 9 \pm 0 \cdot 3$ & $1 \cdot 8 \pm 0 \cdot 3$ & $0 \cdot 9 \pm 0 \cdot 1^{+}$ \\
\hline SUB & $8 \cdot 6 \pm 0.9 *$ & $11 \cdot 3 \pm 0 \cdot 9^{*}$ & $3 \cdot 8 \pm 0 \cdot 7^{*,+}$ \\
\hline MAX & $19 \cdot 2 \pm 1 \cdot 6^{\wedge}$ & $19 \cdot 9 \pm 0 \cdot 8^{\wedge}$ & $15 \cdot 3 \pm 2 \cdot 3^{\wedge}$ \\
\hline
\end{tabular}

Glucose transport was measured as accumulation of ${ }^{14} \mathrm{C}-3-\mathrm{O}-$-methylglucose in individual muscles ( $n=8$ in each of the nine groups). Hindquarters were perfused with insulin concentrations at 0 (BAS), 600 (SUB) and $60000 \mathrm{pmol} / \mathrm{l}(\mathrm{MAX}) .{ }^{\#} P<0.05$ compared with PLA, ${ }^{\S} P<0 \cdot 05$ compared with $\mathrm{GH},{ }^{+} P<0 \cdot 05$ compared with PLA and $\mathrm{GH},{ }^{*} P<0 \cdot 05$ compared with BASAL, ${ }^{\wedge} P<0.05$ compared with BASAL and SUB.

Glucose transport, measured as accumulation of 3-O[glucose $-{ }^{14} \mathrm{C}(\mathrm{U})$ ]methyl-D-glucose in SOL and EDL, increased significantly in all groups with increasing concentrations of insulin (Table 2). In both SOL and EDL there was no difference in glucose transport when PLA was compared with GH at BAS and at MAX. However, at SUB in EDL, glucose transport was slightly but significantly lower in PLA compared with GH, whereas no difference could be detected in SOL (Table 2). In AGE, glucose transport was significantly different from that in GH and PLA at SUB in SOL and at BAS and SUB in EDL (Table 2).

In SOL and EDL, no significant difference in total GLUT1 content was observed when the three experimental groups were compared (Fig. 3). In SOL, no difference in GLUT4 content could be observed when PLA was compared with GH (Fig. 3). In AGE, GLUT4 content was significantly lower than in both GH and PLA (Fig. 3). In EDL, no difference in total GLUT4 content was observed when the three experimental groups were compared (Fig. 3).

In both SOL and EDL, no difference in the maximal activity of CS and LDH was observed when the three experimental groups were compared (Table 3). In SOL, the maximal activity of HAD in GH and AGE was significantly higher than the maximal activity of HAD in PLA (Table 3). There was no difference in the maximal activity of HAD when GH and AGE were compared (Table 3). In the EDL, no difference was observed when the maximal activity of HAD was compared in the three groups (Table 3). In both SOL and EDL, no difference in basal glycogen content was observed when the three experimental groups were compared (Table 3). However, muscle glycogen concentrations generally were higher after perfusion at SUB and MAX compared with BAS (data not shown).

There was no difference in blood glucose concentration when PLA, GH and AGE were compared (Table 4).
A

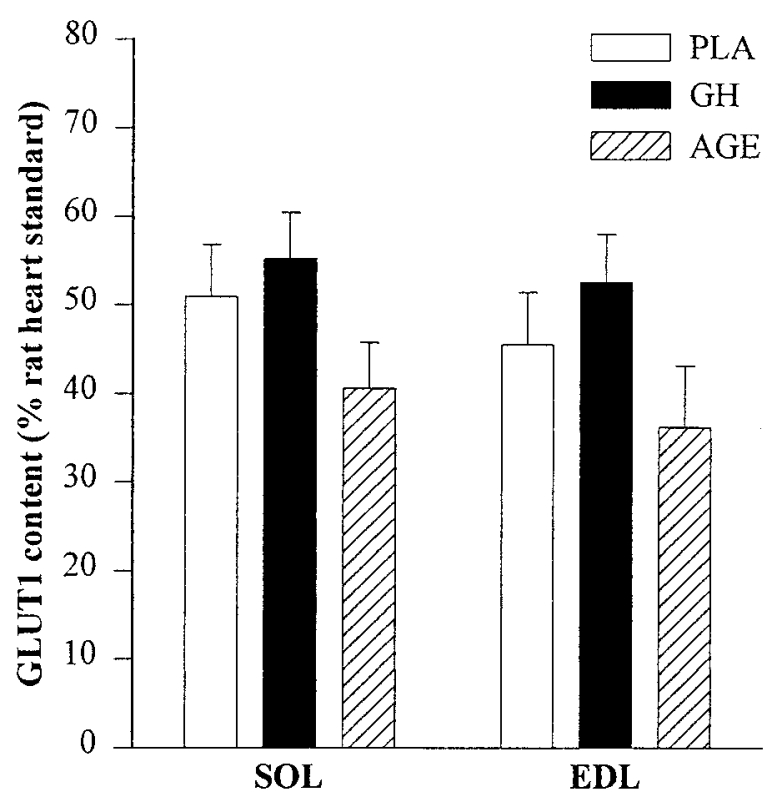

B

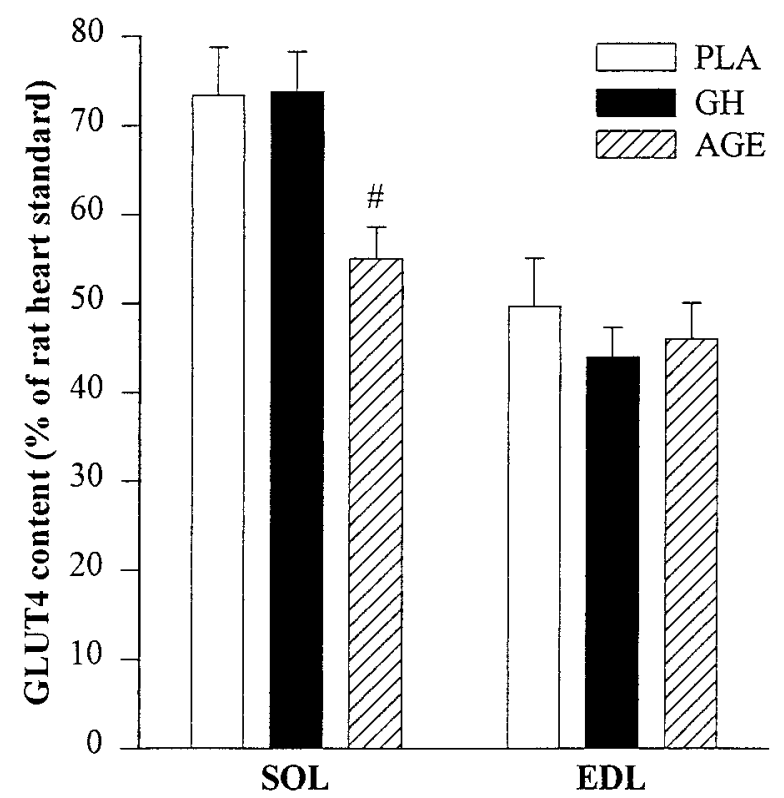

Figure 3 GLUT1 (A) and GLUT4 (B) content was determined by Western blot analysis in SOL and EDL in growth hormone-deficient rats $(\mathrm{GH}$ and $\mathrm{PLA}$ ) and heterozygous age-matched control rats (AGE). Values are expressed relative to a rat heart standard ( $n=8$ in each group). $\# P<0 \cdot 05$ compared with PLA and GH. Values are means \pm S.E.M. 
Table 3 Activities of lactate dehydrogenase (LDH), citrate synthase (CS) and $\beta$-3-hydroxyacyl-CoA dehydrogenase (HAD) and glycogen concentration in growth hormone-deficient rats $(\mathrm{GH}$ and PLA) and heterozygous age-matched control rats (AGE). Values are means \pm S.E.M. $(n=9-10)$

\begin{tabular}{|c|c|c|c|}
\hline & PLA & GH & AGE \\
\hline \multicolumn{4}{|c|}{ LDH $(\mu \mathrm{mol} / \mathrm{g}$ per min) } \\
\hline SOL & $627 \pm 40$ & $637 \pm 42$ & $560 \pm 15$ \\
\hline $\mathrm{EDL}$ & $1984 \pm 93$ & $1963 \pm 114$ & $1944 \pm 92$ \\
\hline \multicolumn{4}{|c|}{ CS $(\mu \mathrm{mol} / \mathrm{g}$ per min $)$} \\
\hline SOL & $42 \cdot 3 \pm 1 \cdot 5$ & $46 \cdot 0 \pm 1 \cdot 2$ & $46 \cdot 2 \pm 1 \cdot 9$ \\
\hline $\mathrm{EDL}$ & $43 \cdot 0 \pm 1 \cdot 7$ & $43 \cdot 3 \pm 2 \cdot 1$ & $41 \cdot 1 \pm 2 \cdot 6$ \\
\hline \multicolumn{4}{|c|}{ HAD $(\mu \mathrm{mol} / \mathrm{g}$ per min $)$} \\
\hline $\mathrm{SOL}$ & $33 \cdot 4 \pm 1 \cdot 6$ & $40 \cdot 8 \pm 2 \cdot 4^{\#}$ & $41 \cdot 5 \pm 2 \cdot 5^{\#}$ \\
\hline $\mathrm{EDL}$ & $15 \cdot 8 \pm 1 \cdot 5$ & $17 \cdot 6 \pm 1 \cdot 4$ & $20 \cdot 5 \pm 1 \cdot 8$ \\
\hline \multicolumn{4}{|c|}{ Glycogen ( $\mu \mathrm{mol}$ glycosyl/g wet weight) } \\
\hline SOL & $34 \cdot 3 \pm 1 \cdot 9$ & $30 \cdot 9 \pm 1 \cdot 0$ & $35 \cdot 2 \pm 1 \cdot 7$ \\
\hline EDL & $36 \cdot 3 \pm 2 \cdot 1$ & $37 \cdot 2 \pm 2 \cdot 2$ & $42 \cdot 2 \pm 2 \cdot 7$ \\
\hline
\end{tabular}

${ }^{\#}$ Significantly different from PLA.

Plasma insulin concentration was similar in PLA and GH (Table 4). In AGE, the plasma insulin concentration was significantly higher than in both PLA and GH (Table 4). In $\mathrm{GH}$ the plasma IGF-I concentration was 23\% higher than in PLA, and in AGE the plasma IGF-I concentration was $38 \%$ higher than in PLA (Table 4). There was no difference in plasma IGF-I concentration when GH and AGE were compared (Table 4). For comparison, IGF-I concentration in normal 15 -week-old Lewis rats without the dwarf gene was $448 \pm 37 \mathrm{ng} / \mathrm{ml}(n=6)$, which was not significantly different from that in GH and AGE.

\section{Discussion}

Our results demonstrate that in growth hormone-deficient rats treatment with growth hormone for 10 days, restoring IGF-I plasma levels to normal, does not change in vitro insulin action in skeletal muscle or the total amount of muscle GLUT1 and GLUT4. On the other hand, in heterozygous non-growth hormone-deficient rats insulin action is decreased compared with the growth hormone-

Table 4 Concentrations of blood glucose, plasma insulin and plasma IGF-I in growth hormone-deficient rats (GH and PLA) and heterozygous age-matched control rats (AGE). Values are means \pm S.E.M.

Blood glucose $(\mathrm{mmol} / \mathrm{l})$

Plasma insulin (pmol/l)

Plasma IGF-I (ng/ml)

\begin{tabular}{|c|c|c|}
\hline PLA & GH & AGE \\
\hline $\begin{array}{l}7 \cdot 7 \pm 0 \cdot 4 \\
(n=24)\end{array}$ & $\begin{array}{l}7 \cdot 9 \pm 0 \cdot 4 \\
(n=24)\end{array}$ & $\begin{array}{l}8 \cdot 9 \pm 0 \cdot 4 \\
(n=21)\end{array}$ \\
\hline $\begin{array}{l}416 \pm 55 \\
(n=20)\end{array}$ & $\begin{array}{l}339 \pm 34 \\
(n=20)\end{array}$ & $\begin{array}{l}751 \pm 88^{+} \\
(n=14)\end{array}$ \\
\hline $\begin{array}{l}364 \pm 23 \\
(n=14)\end{array}$ & $\begin{array}{l}451 \pm 32^{\#} \\
(n=14)\end{array}$ & $\begin{array}{l}503 \pm 46^{\#} \\
(n=10)\end{array}$ \\
\hline
\end{tabular}

${ }^{\#}$ Significantly different from PLA, ${ }^{+}$significantly different from PLA and GH. deficient rats. Thus, chronic growth hormone deficiency is associated with retarded growth and increased insulin action in skeletal muscle. Nevertheless, although weight gain is restored by growth hormone treatment for 10 days, insulin action is not changed.

Several groups have examined the effect of growth hormone on insulin action in rat skeletal muscle. However, most of the information was obtained in hypophysectomised animals (Manchester et al. 1959, Riddick et al. 1962) and in animals bearing a growth hormoneproducing tumour (Imamura et al. 1993) or by adding exogenous growth hormone to already normal levels of hormone ( $\mathrm{Ng}$ et al. 1990, Cartee \& Bohn 1995, Hittiarachchi et al. 1996, Napoli et al. 1996). Our model has clear advantages compared with hypophysectomy, because in the dwarf rat the only deficient anterior pituitary hormone is growth hormone (Charlton et al. 1988). Furthermore, it is more physiologically sound to replace a deficient hormone than to add exogenous hormone on top of endogenous levels.

In the present study, the effect of growth hormone treatment on insulin action was studied in vitro. Consistent with our results Napoli et al. (1996) showed that growth hormone treatment for 4 weeks in normal rats did not change insulin action on skeletal muscle glucose transport. However, other studies in which exogenous growth hormone was added to endogenous secretion for 10 days in normal rats showed a significant but rather small decrease in insulin-stimulated and basal glucose transport in incubated muscles (Dimitriadis et al. 1994, Cartee \& Bohn 1995). In vivo studies on the other hand clearly show that elevation of the growth hormone level for 2-3 days induces peripheral insulin resistance in normal rats $(\mathrm{Ng}$ et al. 1990, Hittiarachchi et al. 1996).

In agreement with studies in rats, studies in normal humans consistently report that short-term infusion of growth hormone decreases peripheral insulin sensitivity (Bratusch-Marrain et al. 1982, Rizza et al. 1982, Rosenfeld et al. 1982, Møller et al. 1989, Bak et al. 1991). Since both insulin binding to its receptor and insulin receptor kinase activity have been shown to be unaffected by growth hormone, the decrease in insulin-mediated glucose uptake seems to be mediated through a postreceptor effect (Bratusch-Marrain et al. 1982, Rosenfeld et al. 1982, Rizza et al. 1982). Thus, most of the available data suggest that the outcome of adding excess growth hormone on top of already normal levels is a decrease in in vivo peripheral insulin sensitivity of glucose metabolism in both rats and humans. However, when insulin action is evaluated in vitro the effects of growth hormone treatment, when added in excess of normal levels or after restoration of subnormal levels, are less consistent.

In line with the view that growth hormone is a diabetogenic hormone, is that it has been shown that growth hormone-deficient children are prone to hypoglycaemia (Goodman et al. 1968, Hopwood et al. 1975) due 
to a diminished hepatic glucose output (Bougnéres et al. 1985). Surprising then is that newer studies in growth hormone-deficient adults show a lower than normal peripheral insulin sensitivity evaluated by the euglycaemic hyperinsulinaemic clamp (Johansson et al. 1995, Hew et al. 1996). The mechanism behind the decrease in insulin action in growth hormone deficiency has not yet been fully elucidated but it has been proposed that a defect in glucose storage and glycogen synthase activation might be involved (Hew et al. 1996). In the present study we were also able to study the effect of chronic growth hormone deficiency on muscle glucose transport by comparing the growth hormone-deficient placebo-treated (PLA) rats with the age-matched heterozygous controls (AGE). We showed that in the SUB state, glucose transport in both SOL and EDL is lower in AGE compared with PLA, whereas no difference could be detected in the BAS and in the MAX states, indicating that insulin sensitivity is decreased in AGE compared with PLA. Since the total level of GLUT1 was the same in PLA and AGE, and GLUT4 was only slightly lower in AGE in SOL, the glucose transporter content does not seem to be able to account for the decrease in insulin sensitivity in AGE. We hypothesise that the difference in body size between PLA and the AGE matched control group is responsible. It is a well known fact that in rats an increase in age is associated with a decrease in insulin sensitivity (Goodman et al. 1983). However, this association between ageing and insulin sensitivity is confounded be several factors such as age-related changes in physical activity, body composition and body size. Changes in physical activity are associated with changed activity of enzymes of the citric acid cycle like CS (Saltin \& Gollnick 1983). The fact that in the present study CS activity was similar in AGE and PLA indicates that the degree of physical activity in the two groups was similar. Because insulin action was determined in individual muscles the reason for the difference between PLA and AGE should be sought in the muscles rather than in the differences in body composition. A possibility is that in the larger AGE rats the diffusion conditions are less favourable than in PLA rats. We have recently demonstrated that the average muscle fibre size is $29-68 \%$ (depending on the muscle fibre type studied) larger in AGE than in PLA (Daugaard et al. 1998). Assuming that the average number of capillaries is the same in muscles from PLA and AGE, then the larger fibre area per capillary means that the average diffusion distance from capillary to muscle fibre surface and interior is increased in AGE compared with PLA. This in turn suggests that the average interstitial concentration of insulin may be less in AGE than in PLA at a given perfusate concentration. Since insulin action is closely related to the interstitial concentration of insulin, as reflected by lymph insulin concentration (Castillo et al. 1994), this might explain the lesser response to SUB and equal response to MAX insulin concentrations in AGE compared with PLA, because at the maximal perfusate insulin concentration interstitial insulin concentration will be well above the maximal stimulating concentration in both groups. It could be argued that the inclusion of a heterozygous weightmatched control group could have clarified whether the size of the rats is responsible for the observed differences. However, by including such a control group the age of the rats would have been introduced as a confounding factor.

Treatment with growth hormone did not have any effect on insulin action in the growth hormone-deficient rats. This is in contrast to older studies using hypophysectomised rats displaying increased insulin action, where both Manchester et al. (1959) and Riddick et al. (1962) observed a normalisation of glucose uptake and 2deoxyglucose transport respectively, following treatment with growth hormone. In humans, several recent studies have assessed insulin action on glucose metabolism in growth hormone-deficient patients receiving replacement therapy with growth hormone (Fowelin et al. 1993, Hussain et al. 1994, Jørgensen et al. 1994, O’Neal et al. 1994, Weaver et al. 1995). It has been shown by most but not all (Hussain et al. 1994, Weaver et al. 1995) that treatment with growth hormone induces a temporary state of insulin resistance which is abolished following longterm treatment (Fowelin et al. 1993, Jørgensen et al. 1994, O'Neal et al. 1994). The mechanisms behind the observed changes are not known, but a change in body composition could be important since adults with growth hormone deficiency are known to have increased body fat mass and decreased lean body mass compared with healthy controls (Binnerts et al. 1992). Furthermore, growth hormone treatment of growth hormone-deficient adults seems to increase lean body mass and decrease adipose tissue mass (Salomon et al. 1989). In the only study of growth hormone-deficient humans examining skeletal muscle it was found that insulin activation of glycogen synthase was less in growth hormone-deficient adults than in controls, as was insulin stimulation of whole body glucose disposal (Hew et al. 1996). This may, however, be an indirect effect of growth hormone deficiency due to differences in body composition, as suggested by Hew et al. (1996). In agreement with this interpretation our study suggests that growth hormone does not alter insulin action directly in muscle.

In conclusion, in growth hormone-deficient rats treatment with growth hormone for 10 days restores weight gain and plasma IGF-I concentration but does not affect in vitro insulin action on skeletal muscle glucose transport. Compared with the growth hormone-deficient rats, agematched control rats have a decreased sensitivity to insulin. This could either indicate a direct long-term effect of growth hormone, or more likely be a secondary effect of increased muscle fibre size making the average diffusion distance longer for insulin from the capillaries to the muscle fibre surface in age-matched control rats compared with growth hormone-deficient rats. 


\section{Acknowledgements}

The authors gratefully acknowledge the excellent technical assistance of Betina Bolmgren and Nina Pluszek, Copenhagen Muscle Research Centre, August Krogh Institute, and Birte M Jørgensen and Kirsten Ravn, Novo Nordisk, Bagsvard, Denmark. Per Norup Jørgensen, Novo Nordisk, is thanked for the GLUT1 and GLUT4 antibody. The study was supported by the Danish National Research Foundation, grant \#504-14. J L L was supported by a student fellowship from Novo Nordisk, Denmark.

\section{References}

Bak JF, Møller N \& Schmitz O 1991 Effects of growth hormone on fuel utilization and muscle glycogen synthase activity in normal humans. American Journal of Physiology 260 E736-E742.

Binnerts A, Deurenberg P, Swart GR, Wilson JHP \& Lamberts SWJ 1992 Body composition in growth hormone deficient adults. American Journal of Clinical Nutrition 55 918-923.

Bougnéres P-F, Artavia-Loria E, Ferre P, Chaussain J-L \& Job J-C 1985 Effects of hypopituitarism and growth hormone replacement therapy on the production and utilization of glucose in childhood. Journal of Clinical Endocrinology and Metabolism 61 1152-1157.

Bratusch-Marrain PR, Smith D \& DeFronzo RA 1982 The effect of growth hormone on glucose metabolism and insulin secretion in man. Journal of Clinical Endocrinology and Metabolism 55 973-982.

Cartee GD \& Bohn EE 1995 Growth hormone reduces glucose transport but not GLUT-1 or GLUT-4 in adult and old rats. American Journal of Physiology 268 E902-E909.

Castillo C, Bogardus C, Bergman R, Thuillez P \& Lillioja S 1994 Interstitial insulin concentrations determine glucose uptake rates but not insulin resistance in lean and obese men. Journal of Clinical Investigation 93 10-16.

Charlton HM, Clark RG, Robinson ICAF, Goff AEP, Cox BS, Bugnon C \& Bloch BA 1988 Growth hormone-deficient dwarfism in the rat: a new mutation. Journal of Endocrinology 119 51-58.

Daugaard JR, Laustsen JL, Hansen BS \& Richter EA 1998 Growth hormone induces muscle fibre type transformation in growth hormone deficient rats. Acta Physiologica Scandinavica 164 119-126.

Dimitriadis G, Perry-Billings M, Leighton B, Piva T, Dunger D, Calder P, Bond J \& Newsholme EA 1994 Studies on the effect of growth hormone administration in vivo on the rates of glucose transport and utilization in rat skeletal muscle. European Journal of Clinical Investigation 24 161-165.

Fink RI, Kolterman OG, Griffin J \& Olefsky JM 1983 Mechanisms of insulin resistance in aging. Journal of Clinical Investigation $\mathbf{7 1}$ 1523-1535.

Fowelin J, Attwelin S, Lager I \& Bengtsson B- 1993 Effects of treatment with recombinant human growth hormone on insulin sensitivity and glucose metabolism in adults with growth hormone deficiency. Metabolism 42 1443-1447.

Goodman HG, Grumbach MM \& Kaplan SL 1968 Growth and growth hormone II. A comparison of isolated growth-hormone deficiency and multiple pituitary-hormone deficiencies in 35 patients with idiopathic hypopituitary dwarfism. New England Journal of Medicine 278 57-68.

Goodman MN, Dluz SM, McElaney MA, Belur E \& Ruderman NB 1983 Glucose uptake and insulin sensitivity in rat muscle: changes during 3-96 weeks of age. American Journal of Physiology 244 E93-E100.

Hew FL, Koschmann M, Christopher M, Rantzau C, Vaag A, Ward G, Beck-Nielsen H \& Alford F 1996 Insulin resistance in growth hormone-deficient adults: defects in glucose utilization and glycogen synthase activity. Journal of Clinical Endocrinology and Metabolism 81 555-564.

Hittiarachchi M, Watkinson A, Jenkins AB, Theos V, Ho KKY \& Kraegen EW 1996 Growth hormone-induced insulin resistance and its relation to lipid availability in the rat. Diabetes 45 415-421.

Hopwood NJ, Forsman PJ, Kenny FM \& Drash AL 1975 Hypoglycemia in hypopituitary children. American Journal of Disabled Children 129 918-929.

Hussain MA, Schmitz O, Mengel A, Glatz Y, Christiansen JS, Zapf J \& Froesch ER 1994 Comparison of the effects of growth hormone and insulin-like growth factor I on substrate oxidation and on insulin sensitivity in growth hormone-deficient humans. Journal of Clinical Investigation 94 1126-1133.

Imamura H, Morimoto I, Etoh S, Usa T, Namba H, Ohtsuru A, Yokota A, Nagataki S \& Yamashita S 1993 Skeletal muscle glucose transporter gene expression is not affected by injecting growthhormone-secreting cells in young rats. Diabetologia 36 475-480.

Johansson J-O, Fowelin J, Landin K, Lager I \& Bengtsson B-Å 1995 Growth hormone-deficient adults are insulin-resistant. Metabolism 44 1126-1129.

Jørgensen JOL, Thuesen L, Møller J, Ovesen P, Skakkebæk NE \& Christiansen JS 1994 Three years of growth hormone treatment in growth hormone-deficient adults: near normalization of body composition and physical performance. European Journal of Endocrinology 130 224-228.

Lowry OH \& Passonneau JV 1972 A Flexible System of Enzymatic Analysis. New York: Academic Press.

Manchester KL, Randle PJ \& Young FG 1959 The effect of growth hormone and of cortisol on the response of isolated rat diaphragm to the stimulating effect of insulin on glucose uptake and on incorporation of amino acids into protein. Journal of Endocrinology 18 395-408.

Møller N, Butler P, Antsiverov M \& Alberti KGM 1989 Effects of growth hormone on insulin sensitivity and forearm metabolism in normal man. Diabetologia 32 105-110.

Napoli R, Cittadini A, Chow JC, Hirshman MF, Smith RJ, Douglas PS \& Horton ES 1996 Chronic growth hormone treatment in normal rats reduces post-prandial skeletal muscle plasma membrane GLUT1 content, but not glucose transport or GLUT4 expression and localization. Biochemical Journal 315 959-963.

Ng SF, Storlien LH, Kraegen EW, Stuart MC, Chapman GE \& Lazarus L 1990 Effect of biosynthetic human growth hormone on insulin action in individual tissues of the rat in vivo. Metabolism 39 264-268.

O’Neal DN, Kalfas A, Dunning PL, Christopher MJ, Sawyer SD, Ward GM \& Alford FP 1994 The effect of 3 months of recombinant human growth hormone $(\mathrm{GH})$ therapy on insulin and glucose-mediated glucose disposal and insulin secretion in GH-deficient adults: a minimal model analysis. Journal of Clinical Endocrinology and Metabolism 79 975-983.

Ploug T, Wojtaszewski J, Kristiansen S, Hespel P, Galbo H \& Richter EA 1993 Glucose transport and transporters in muscle giant vesicles: differential effects of insulin and contractions. American Journal of Physiology 264 E270-E278.

Richter EA 1996 Glucose utilization. In Handbook of Physiology, section 12: Exercise: regulation and integration of multiple systems, pp 912-951. Eds LB Rowell \& JT Shepherd. New York: American Physiological Society.

Richter EA, Ruderman NB, Gavras H, Belur ER \& Galbo H 1982 Muscle glycogenolysis during exercise: dual control by epinephrine and contractions. American Journal of Physiology 242 E25-E32.

Richter EA, Garetto LP, Goodman MN \& Ruderman NB 1984 Enhanced muscle glucose metabolism after exercise: modulation by local factors. American Journal of Physiology 246 E476-E482.

Riddick FA, Reisler DM \& Kipnis DM 1962 The sugar transport system in striated muscle: effect of growth hormone, hydrocortisone and alloxan diabetes. Diabetes 11 171-178. 
Rizza RA, Mandarino LJ \& Gerich JE 1982 Effects of growth hormone on insulin action in man. Diabetes 31 663-669.

Rosenfeld RG, Wilson DM, Dollar LA, Bennett A \& Hintz RL 1982 Both human pituitary growth hormone and recombinant DNAderived human growth hormone cause insulin resistance at a postreceptor site. Journal of Clinical Endocrinology and Metabolism $\mathbf{5 4}$ 1033-1038.

Ruderman NB, Houghton R \& Hems R 1971 Evaluation of the isolated perfused rat hindquarter for the study of muscle metabolism. Biochemical Journal 124 639-651.

Salomon F, Cuneo RC, Hesp R \& Sönksen PH 1989 The effects of treatment with recombinant human growth hormone on body composition and metabolism in adults with growth hormone deficiency. New England Journal of Medicine 321 1797-1803.

Saltin B \& Gollnick PD 1983 Skeletal muscle adaptability: significance for metabolism and performance. In Handbook of Physiology, section
10: Skeletal muscle, pp 555-631. Eds LD Peachey, RH Adrian \&

SR Geiger. Bethesda: American Physiological Society.

Schäffer L, Larsen UD, Linde S, Skriver L \& Hejnæs K 1992 Receptor binding of the three isomers of ${ }^{125}$ I-labeled insulin-like growth factor I. Diabetologia 35 A83.

Weaver JU, Monson JP, Noonan K, John WG, Edwards A, Evans KA \& Cunningham J 1995 The effect of low dose recombinant human growth hormone replacement on regional fat distribution, insulin sensitivity, and cardiovascular risk factors in hypopituitary adults. Journal of Clinical Endocrinology and Metabolism $\mathbf{8 0}$ 153-159.

Received 25 March 1998 Accepted 22 September 1998 